\title{
Persepsi Tentang Perawatan Gigi Tiruan Pada Masyarakat Kelurahan Maasing Kecamatan Tuminting Kota Manado
}

\author{
${ }^{1}$ Andriani Silviana, ${ }^{2}$ Vonny NS. Wowor, ${ }^{2}$ Ni Wayan Mariati \\ ${ }^{1}$ Mahasiswa Program Studi Kedokteran Gigi Fakultas Kedokteran Universitas Sam Ratulangi Manado \\ ${ }^{2}$ Dosen di Program Studi Kedokteran Gigi Fakultas Kedokteran Universitas Sam Ratulangi
}

\begin{abstract}
ABSTRAK
Kehilangan gigi dapat mengakibatkan terganggunya beberapa fungsi, yakni fungsi penggunyahan, bicara, dan estetik. Akibat adanya dampak yang ditimbulkan maka seharusnya gigi yang hilang diganti dengan gigi tiruan, namun tidak semua orang yang mengalami kehilangan gigi memakai gigi tiruan. Salah satu faktor pendorong bagi seseorang dalam pengambilan keputusan untuk menggunakan gigi tiruan yaitu persepsi individu terhadap berbagai hal yang berkaitan dengan perawatan gigi tiruan. Persepsi adalah proses akhir dari pengamatan yang diawali proses penginderaan, yaitu merupakan proses diterimanya stimulus oleh alat indera kemudian terjadi perhatian, diteruskan ke otak, dan individu menyadari tentang sesuatu. Penelitian ini merupakan suatu penelitian deskriptif dengan tujuan untuk mengetahui persepsi masyarakat kelurahan Maasing kecamatan Tuminting tentang perawatan gigi tiruan. Penelitian dilakukan selang bulan April 2013 hingga Oktober 2013, dimana pengambilan data penelitian dilakukan pada bulan Agustus 2013. Sampel yang digunakan memenuhi kriteria inklusi dengan ukuran sampel sebanyak 108 dan pengambilannya menggunakan purposive sampling method. Hasil penelitian menunjukkan persepsi masyarakat tentang perawatan gigi tiruan secara umum baik, dimana persepsi masyarakat berdasarkan tujuan perawatan gigi tiruan, baik (skor 363,33); persepsi masyarakat berdasarkan manfaat perawatan gigi tiruan, baik (skor 388); dan persepsi masyarakat berdasarkan prosedur perawatan gigi tiruan, cukup baik dengan skor penilaian 328,25.
\end{abstract}

Kata kunci : Persepsi masyarakat, kehilangan gigi, perawatan gigi tiruan

\begin{abstract}
Tooth loss can lead to disruption of some of functions like mastication, speech, and aesthetic function. Seeing the impact of losing tooth, it should replaced with dentures, but not all people who have lost teeth wear dentures. One of the driving factors in the decision for a person to use a denture that individual's perception of a variety of matters related to denture care. Perception is the process by the end of the observation that begins the process of sensing, which is the process of receiving stimulus by the sensory organs and then going concern, transmitted to the brain, and the individual is aware of something. This research is a descriptive study with the aim to determine the public perception of urban districts Maasing Tuminting about denture care. The study was conducted in April 2013 to lapse in October 2013 , where research data collection was conducted in August 2013. The sample used met the inclusion criteria with a sample size of 108 and from using puposive sampling method. The results showed people's perception about denture care is generally good, with public perception based on objective good denture care (score 363.33) ; public perception based on the benefits of good denture care (score 388), and perceptions based on dental care procedures pretty good imitation with a score of (328.25) assessment .
\end{abstract}

Keywords: Public perception, tooth loss, denture care

Koresponden: Andriani Silviana, Program Studi Kedokteran Gigi Fakultas Kedokteran Universitas Sam Ratulangi. E-mail: silvi_8888@yahoo.com

\section{PENDAHULUAN}

Gigi merupakan salah satu organ tubuh yang memiliki fungsi yang penting bagi tubuh. Gigi yang rusak, tidak teratur susunannya, ataupun yang hilang bisa berdampak pada kesehatan. Kesehatan gigi merupakan salah satu cermin kesehatan manusia, oleh karena merupakan bagian integral dari kesehatan secara keseluruhan. Sehat sebagaimana yang didefinisikan oleh World Health Organization (WHO), mencakup kesehatan fisik, sosial dan mental. ${ }^{1}$ Gigi yang tidak sehat atau bermasalah bukan saja berdampak pada kesehatan fisik, namun juga kesehatan sosial maupun mental.
Seseorang yang mengalami kehilangan gigi dan tidak segera diganti akan mengakibatkan terganggunya beberapa fungsi, yakni fungsi pengunyahan, fungsi bicara dan fungsi estetik. Tidak adanya gigi, baik sebagian ataupun seluruhnya dapat menyebabkan pengunyahan makanan menjadi kurang maksimal. Dampak lainnya berupa gangguan dalam bicara ataupun pengucapan kata-kata dalam huruf tertentu, serta terganggunya penampilan seseorang. Kesemuanya ini dapat mengakibatkan ketidaknyamanan atau hambatan dalam beraktivitas. ${ }^{2}$

Pada beberapa profesi yang berhadapan langsung dengan publik, penampilan menjadi 
sesuatu yang penting. Senyuman yang indah dengan deretan gigi yang rapih dan lengkap merupakan salah satu dambaan setiap orang. Penampilan yang kurang sempurna akibat hilangnya gigi yang tidak diganti berdampak pada berkurangnya hingga hilangnya kepercayaan diri. Kondisi ini dapat membuat seseorang menjadi malas beraktivitas. Produktivitas kerja yang menurun akhirnya berdampak pada berkurangnya kualitas hidup seseorang. Oleh karena itu dikatakan bahwa kesehatan gigi merupakan salah satu hasil interaksi antara kondisi fisik, sosial dan mental seseorang. ${ }^{3}$

Kehilangan gigi bisa dialami oleh siapa saja tanpa memandang usia ataupun jenis kelamin. Penyebabnya pun bisa beragam, yakni karena alasan fisiologis ataupun kehilangan yang diakibatkan buruknya status kesehatan gigi terutama oleh karena penyakit periodontal, trauma, karies. Penyebab lainnya diakibatkan oleh kegagalan perawatan sebelumnya, serta kelainan atau gangguan pertumbuhan. ${ }^{4}$

Idealnya kehilangan gigi harus dibuatkan penggantinya untuk mengantisipasi berbagai gangguan yang mungkin saja terjadi, namun data yang ada menunjukkan bahwa belum semua kehilangan gigi dibuatkan penggantinya. Data Hasil Riset Kesehatan Dasar (RISKESDAS) 2007 memperlihatkan, bahwa sebagian besar masyarakat berumur 45-65 tahun keatas $(25,3 \%)$ mengalami kehilangan gigi, namun sayangnya hanya $7,1 \%$ yang melakukan penggantian terhadap giginya yang hilang. ${ }^{5}$ Alasan yang melatarbelakangi seseorang mengambil keputusan untuk melakukan penggantian gigi dipengaruhi oleh berbagai faktor. Faktor persepsi merupakan salah satu faktor yang berpengaruh. ${ }^{6}$

Persepsi adalah sebuah proses stimulus yang diinderakan oleh individu dan kemudian diinterprestasikan, sehingga individu dapat menyadari, mengerti tentang apa yang diinderakan. $^{7} \quad$ Penelitian yang dilakukan oleh Shigli dkk di Institusi Sains Kedokteran Gigi, Belgaum, India untuk menilai persepsi terhadap pemakaian gigi tiruan pada pasien yang berobat ke Institusi tersebut, memperlihatkan semua pasien mengatakan bahwa mereka mau memakai gigi tiruan, namun kenyataannya belum seluruhnya memakai gigi tiruan. Kira-kira 20\% pasien mengatakan tidak memakai gigi tiruan karena kesulitan keuangan, 7,1\% mengatakan tidak ada waktu ke dokter gigi, 6,9\% mengatakan tidak perlu, dan $3,8 \%$ mengatakan kurang pengetahuan tentang perawatan gigi tiruan. ${ }^{8}$

Perawatan gigi tiruan adalah perawatan yang ditujukan untuk menggantikan gigi yang hilang dan jaringan lunak di sekitarnya dengan suatu alat tiruan. Alat tiruan ini digunakan dengan tujuan agar fungsi pengunyahan, fungsi bicara dan fungsi estetik yang hilang bisa dikembalikan dan kesehatan jaringan pendukung tetap dipertahankan dalam keadaan optimal. ${ }^{9}$ Banyaknya individu yang tidak memahami pentingnya penggunaan gigi tiruan menjadi salah satu penyebab pasien yang kehilangan gigi tidak menggunakan gigi tiruan.

Kelurahan Maasing adalah salah satu kelurahan di kecamatan Tuminting, dengan jumlah penduduk keseluruhan sebesar 4092 jiwa,yang terdiri dari $1575 \mathrm{KK}$. Survei awal yang dilakukan pada 30 individu di kelurahan tersebut, menunjukkan bahwa 26 di antaranya mengalami kehilangan gigi dan tidak menggunakan gigi tiruan dengan berbagai alasan.

Tidak adanya data statistik tentang keadaan ini serta adanya beberapa alasan tersebut di atas membangkitkan minat penulis untuk meneliti tentang persepsi masyarakat tentang perawatan gigi tiruan di kelurahan Maasing kecamatan Tuminting.

\section{BAHAN DAN METODE}

Penelitian yang dilakukan merupakan jenis penelitian deskriptif dan dilaksanakan di Kelurahan Maasing Kecamatan Tuminting Kota Manado. Sampel dalam penelitian ini yaitu masyarakat yang mengalami kehilangan gigi namun tidak menggunakan gigi tiruan. Besar sampel diperoleh dengan menggunakan rumus Slovin, yaitu sebanyak 108 orang. Pengambilan sampel dilakukan dengan teknik purposive sampling, dimana sampel diambil berdasarkan pertimbangan peneliti yaitu sesuai kriteria inklusi dan eksklusi yang telah ditetapkan.

Kriteria inklusi yaitu berusia 17 sampai 70 tahun, memiliki kehilangan gigi sekurangkurangnya satu elemen, tidak menggunakan gigi tiruan, bersedia dengan suka rela untuk menjadi subjek dalam penelitian ini. Sedangkan kriteria eksklusi yaitu menggunakan gigi tiruan, tidak bersedia menjadi subjek penelitian, tidak kooperatif dalam peoses penelitian, tidak berada di tempat pada saat penelitian. Penelitian ini diawali dengan adanya surat pengantar permohonan ijin penelitian yang diperoleh dari Program Studi Kedokteran Gigi. Penelitian dimulai setelah dikeluarkannya ijin dari pihak kelurahan Maasing kecamatan Tuminting. Responden yang terpilih sebagai subjek penelitian, dimintakan persetujuan terlebih dahulu dan persetujuan dibuktikan dengan adanya 
penandatangan surat persetujuan (informed consent), barulah penelitian dilakukan dengan mengedarkan kuesioner untuk dijawab. Penelitian ini dilakukan dengan menggunakan data primer dan data sekunder. Data primer diperoleh secara langsung dari responden melalui wawancara dan kuesioner pada masyarakat kelurahan Maasing kecamatan Tuminting kota Manado yang langsung ditemui di rumah-rumah masyarakat. Data sekunder diperoleh dari profil kelurahan berupa identitas kelurahan dan jumlah masyarakat. Untuk memperoleh penilaian terhadap persepsi masyarakat, pertanyaan dalam kuesioner diukur menggunakan skala Likert, yaitu setiap jawaban pertanyaan diberi nilai/skor 1 hingga 5, sebagai berikut:

$\begin{array}{ll}\text { Tidak setuju } & =1 \\ \text { Kurang setuju } & =2 \\ \text { Setuju } & =3 \\ \text { Sangat setuju } & =4 \\ \text { Amat sangat setuju } & =5\end{array}$

Cara menghitung skor dalam penelitian yaitu dengan mengalikan jumlah responden yang menjawab sesuai dengan pilihan alternatif jawaban (A) dengan nilai masing-masing alternatif jawaban (B) sebagai berikut:

Jumlah skor per jawaban pertanyaan $=\mathrm{A} \times \mathrm{B}$

Jumlah skor tertinggi $=108 \times 5=540$

Jumlah skor terendah $=108 \times 1=108$

Data hasil pengukuran secara kontinum dapat dilihat seperti:

\begin{tabular}{llllll}
\multicolumn{1}{c}{ kurang } & & cukup & & Baik & \\
108 & 180 & & 360 & & 540
\end{tabular}

Data dikumpulkan dan pengolahan data dilakukan secara manual kemudian dianalisa berdasarkan persentase dan disajikan dalam bentuk tabel dan diagram distribusi frekuensi.

\section{HASIL PENELITIAN}

Tabel 1. Distribusi frekuensi responden berdasarkan usia.

\begin{tabular}{ccc}
\hline Rentang Usia & $\begin{array}{c}\text { Jumlah Responden } \\
(\mathrm{N})\end{array}$ & $\begin{array}{c}\text { Persentase } \\
(\%)\end{array}$ \\
\hline $17-25$ tahun & 10 & 9,26 \\
$26-35$ tahun & 25 & 23,15 \\
$36-45$ tahun & 34 & 31,48 \\
$46-55$ tahun & 22 & 20,37 \\
$56-65$ tahun & 13 & 12,04 \\
$66>$ tahun & 4 & 3,70 \\
\hline Total & 108 & $100 \%$ \\
\hline
\end{tabular}

Tabel 1 menunjukkan bahwa dari 108 responden diketahui jumlah responden terbanyak pada rentang usia 36-45 tahun dengan jumlah 34 responden $(31,48 \%)$, selanjutnya pada rentang usia 26-35 tahun berjumlah 25 responden $(23,15 \%)$, rentang usia $46-55$ tahun berjumlah 22 responden $(20,37 \%)$, rentang usia 56-65 tahun berjumlah 13 responden $(12,04 \%)$, rentang usia 17-25 tahun berjumlah 10 responden $(9,26 \%)$, dan yang paling sedikit pada rentang 66> tahun berjumlah 4 responden $(3,70 \%)$.

Tabel 2. Distribusi frekuensi responden berdasarkan jenis kelamin

\begin{tabular}{lcc}
\hline Jenis Kelamin & $\begin{array}{c}\text { Jumlah } \\
\text { Responden }(\mathrm{N})\end{array}$ & $\begin{array}{c}\text { Persentase } \\
(\%)\end{array}$ \\
\hline Laki-laki & 32 & 29,63 \\
Perempuan & 76 & 70,37 \\
\hline \multicolumn{1}{c}{ Total } & 108 & 100 \\
\hline
\end{tabular}

Tabel 2 menunjukkan bahwa dari 108 responden diketahui 32 responden $(29,63 \%)$ berjenis kelamin laki-laki dan 76 responden $(70,37 \%)$ berjenis kelamin perempuan.

Tabel 3. Distribusi frekuensi responden berdasarkan tingkat pendidikan

\begin{tabular}{ccc}
\hline $\begin{array}{c}\text { Tingkat } \\
\text { Pendidikan }\end{array}$ & $\begin{array}{c}\text { Jumlah Responden } \\
(\mathrm{N})\end{array}$ & $\begin{array}{c}\text { Persentase } \\
(\%)\end{array}$ \\
\hline SD & 43 & 39,81 \\
SMP & 26 & 24,07 \\
SMA & 38 & 35,19 \\
S1 & 1 & 0,39 \\
\hline Total & 108 & 100 \\
\hline
\end{tabular}

Tabel 3 menunjukkan bahwa dari 108 responden diketahui jumlah responden dengan tingkat pendidikan SD merupakan responden terbanyak dengan jumlah 43 responden $(39.81 \%)$, selanjutnya SMA berjumlah 38 responden $(35,19 \%)$, SMP berjumlah 26 responden $(24,07 \%)$, dan yang paling sedikit yaitu responden dengan tingkat pendidikan $\mathrm{S} 1$ berjumlah 1 responden $(0,93 \%)$. 
Tabel 7. Distribusi frekuensi penilaian persepsi tentang tujuan perawatan gigi tiruan.

\begin{tabular}{|c|c|c|c|c|c|c|c|}
\hline \multirow[b]{2}{*}{ No } & \multirow{2}{*}{ Tujuan Perawatan Gigi Tiruan } & \multicolumn{5}{|c|}{ Persepsi } & \multirow[b]{2}{*}{ Skor } \\
\hline & & TS & $\mathrm{KS}$ & $\mathrm{S}$ & SS & ASS & \\
\hline 1 & Agar dapat mengunyah dengan baik & 11 & 38 & 159 & 52 & 60 & 320 \\
\hline 2 & $\begin{array}{l}\text { Agar bisa berbicara kembali dengan } \\
\text { baik }\end{array}$ & 7 & 32 & 153 & 72 & 80 & 344 \\
\hline \multirow[t]{3}{*}{3} & $\begin{array}{l}\text { Agar enak dipandang/tidak terlihat } \\
\text { ompong }\end{array}$ & 2 & 0 & 105 & 144 & 175 & 426 \\
\hline & & & & & & Total & 1090 \\
\hline & & & & & & r rata2 & 363,33 \\
\hline
\end{tabular}

363,33

kurang

108 cukup

180
Baik

360

Tabel 10. Distribusi penilaian persepsi responden tentang manfaat perawatan gigi tiruan.

\begin{tabular}{|c|c|c|c|c|c|c|c|}
\hline \multirow{2}{*}{ No } & \multirow{2}{*}{ Manfaat perawatan gigi tiruan } & \multicolumn{5}{|c|}{ Persepsi } & \multirow{2}{*}{ Skor } \\
\hline & & TS & $\mathrm{KS}$ & $\mathrm{S}$ & SS & ASS & \\
\hline 1 & Menggantikan fungsi gigi asli yang hilang & 7 & 12 & 186 & 80 & 65 & 350 \\
\hline \multirow[t]{3}{*}{2} & $\begin{array}{l}\text { Mengembalikan rasa percaya diri akibat kehilangan } \\
\text { gigi }\end{array}$ & 0 & 4 & 111 & 136 & 175 & 426 \\
\hline & & & & & & Total & 776 \\
\hline & & & & & Skc & ata-rata & 388 \\
\hline
\end{tabular}

kurang

108 cukup

360
Baik

180

Tabel 15. Distribusi penilaian persepsi responden tentang prosedur perawatan gigi tiruan

\begin{tabular}{|c|c|c|c|c|c|c|c|}
\hline \multirow[b]{2}{*}{ No } & \multirow[b]{2}{*}{ Prosedur perawatan gigi tiruan } & \multicolumn{5}{|c|}{ Persepsi } & \multirow[b]{2}{*}{ Skor } \\
\hline & & TS & $\mathrm{KS}$ & S & SS & ASS & \\
\hline 1 & Memerlukan biaya yang mahal & 13 & 50 & 105 & 84 & 70 & 322 \\
\hline 2 & Menyita waktu (kunjungan bolak balik) & 18 & 36 & 141 & 56 & 55 & 306 \\
\hline 3 & $\begin{array}{l}\text { Dokter gigi merupakan tenaga yang memiliki keahlian } \\
\text { dan ijin untuk melakukan perawatan gigi tiruan }\end{array}$ & 0 & 10 & 147 & 76 & 175 & 408 \\
\hline \multirow[t]{3}{*}{4} & Perawatan gigi tiruan tidak nyaman & 31 & 44 & 87 & 60 & 55 & 277 \\
\hline & & & & & & Total & 1313 \\
\hline & & & & & Sko & ta-rata & 328.25 \\
\hline
\end{tabular}




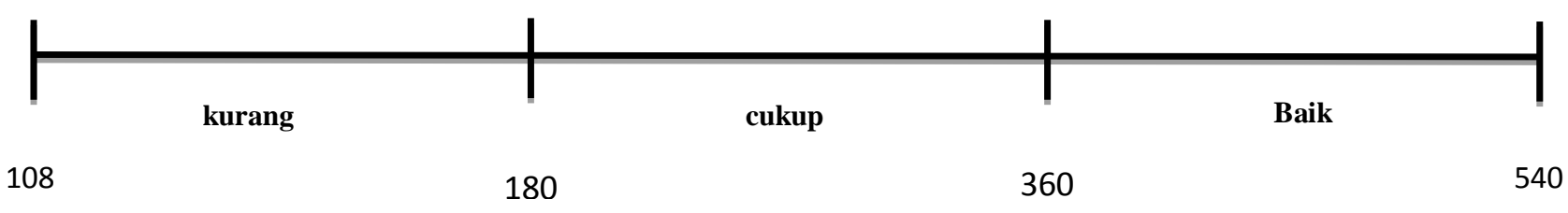

\section{PEMBAHASAN}

\section{Tujuan perawatan gigi tiruan}

Dari hasil penelitian tentang persepsi reseponden terhadap tujuan perawatan gigi tiruan pada masyarakat kelurahan Maasing kecamatan Tuminting, didapatkan penilaian skor rata-rata sebesar 363,33.Penilaian ini masuk dalam kategori baik.Responden terbanyak memilih alternatif jawaban pada atribut setuju hingga amat sangat setuju. Hasil ini menggambarkan bahwa sebagian besar responden telah memahami sehingga memiliki persepsi yang baik tentang tujuan perawatan gigi tiruan, yakni agar dapat mengunyah dengan baik, dapat berbicara kembali dengan baik serta enak dipandang atau tidak terlihat ompong.

Berdasarkan penelitian yang dilakukan oleh Moynihan pada tahun 2007, kelancaran pengunyahan makanan di dalam rongga mulut bergantung pada kelengkapan susunan gigi. Jumlah gigi geligi yang tidak lengkap akan menurunkan keefektifan fungsi pengunyahan. ${ }^{10}$ Setiap gigi mempunyai fungsinya masing-masing dalam proses pengunyahan. Gigi insisivus berfungsi untuk memotong dan menggigit makanan, gigi kaninus berfungsi untuk menyobek atau mengoyak makanan, gigi premolar berfungsi untuk menghancurkan dan menggiling makanan, serta gigi molar berfungsi untuk menghancurkan makanan.Mengingat fungsinya maka kehilangan gigi yang tidak digantikan dapat menyebabkan gangguan pada fungsi pengunyahan karena makanan tidak bisa dihancurkan dengan baik dalam mulut.

Hal tersebut didukung oleh suatu penelitian yang dilakukan oleh Johanes dkk pada tahun 2009 yang menunjukkan bahwa pasien dengan kehilangan gigi sebagian menghindari memakan makanan tertentu, contohnya buah dan sayuran yang berserat karena memiliki membran selulosa yang sulit dicerna. Demikian halnya dalam pengunyahan makanan yang keras seperti daging, dll. Hal ini akan menyebabkan pasien mengalami penurunan asupan nutrisi. ${ }^{11}$ Selain itu kehilangan gigi juga berdampak pada cara berbicara seseorang, oleh karena hilangnya gigi dapat mengakibatkan kesulitan dalam pengucapan huruf dalam konsonan tertentu. ${ }^{12}$ Pembuatan gigi tiruan diharapkan dapat mengembalikan fungsi pengunyahan dan fungsi bicara seseorang sehingga menjadi normal kembali.

Kehilangan gigi dapat pula menyebabkan munculnya reaksi emosional seperti rasa sedih, dan kehilangan rasa percaya diri. Rasa percaya diri akan lebih berkurang apabila kehilangan terjadi pada gigi bagian depan (anterior), karena dapat memengaruhi penampilan. Adanya gigi tiruan untuk menggantikan gigi yang hilang dapat mengembalikan rasa percaya diri seseorang, sehingga gangguan yang timbul dapat diatasi.

Pada penelitian ini alasan responden tidak menggunakan gigi tiruan mungkin dikarenakan mahalnya biaya perawatan, atau dikarenakan alasan waktu serta ketersediaan dan keterjangkauan sarana pelayanan atau ketersediaan petugas medis yang berkompeten. Apabila dikaitkan dengan latar belakang responden serta kondisi yang ada, penulis berpendapat bahwa kemungkinan terbesar para responden tidak menggunakan gigi tiruan dikarenakan alasan biaya atau status ekonomi. Hal ini didukung oleh karakteristik responden yang sebagian besar bermatapencaharian sebagai buruh pelabuhan, ataupun sebagai pedagang kecilkecilan, padahal mereka harus menghidupi keluarga. Dengan demikian perawatan gigi tiruan bukan menjadi prioritas utama dalam kehidupan sehari-hari mereka.

\section{Manfaat perawatan gigi tiruan}

Skor penelitian rata-rata tentang persepsi responden terhadap manfaat perawatan gigi tiruan adalah 388. Penilaian tersebut masuk dalam kategori baik.Sama seperti di atas, responden terbanyak memilih alternatif jawaban pada atribut setuju hingga amat sangat setuju. Hal ini menggambarkan bahwa sebagian besar responden yang adalah individu yang kehilangan gigi namun tidak menggunakan gigi tiruan telah paham tentang fungsi atau manfaat perawatan gigi tiruan. 
Dari capaian hasil skor yang paling tinggi terlihat bahwa persepsi responden tentang fungsi atau manfaat gigi tiruan lebih ditujukan untuk mengembalikan rasa percaya diri akibat kehilangan gigi. Hal ini bisa dimaklumi karena kehilangan gigi depan dapat menganggu penampilan seseorang terlebih jika pasien mengalami kehilangan gigi bagian depan. Berdasarkan penelitian yang dilakukan oleh Sasmita dkk pada tahun 2007, akibat dari kehilangan gigi terutama bila terjadi di bagian depan dalam jumlah yang banyak akan memperlihatkan wajah dengan bentuk bibir masuk ke dalam, sehingga dasar hidung tampak lebih kedalam dan dagu terlihat lebih ke depan. Selain itu akan muncul lipatan-lipatan yang tidak sesuai dengan usia penderita dan menimbulkan kesan lebih tua dari usia sebenarnya. Bagi sebagian orang yang memiliki aktivitas sehari-hari berkontak dengan banyak orang, akan merasa sangat terganggu dengan kehilangan gigi depan. Kehilangan gigi belakang tidak begitu berpengaruh dibandingkan kehilangan gigi depan, apabila dikaitkan dengan penampilan. Elias dan Sheiham mengatakan bahwa segi penampilan atau nilai estetika yang diperoleh merupakan hal yang lebih penting dibandingkan fungsi. Umumnya kekhawatiran pasien tentang penilaiaan estetika muncul apabila mengalami kehilangan gigi anterior. ${ }^{13}$

Di samping itu juga kehilangan gigi dapat menimbulkan kesulitan dalam proses pengucapan beberapa huruf konsonan. Pengucapan huruf konsonan menjadi tidak sempurna sehingga dapat menyebabkan gangguan psikologis serta dapat menyebabkan hilangnya kepercayaan diri. Menurut penelitian Polsani dkk pada tahun 1961, kehilangan gigi anterior atas dan bawah akan menyebabkan kelainan bicara, karena gigi anterior termasuk bagian organ fonetik. Sebagian besar orang beranggapan bahwa kehilangan gigi merupakan suatu hal yang besar sehingga gigi tiruan sangat penting untuk menggantikan gigi geligi yang hilang untuk kelanjutan kehidupan yang normal. ${ }^{14}$

Hasil penelitian ini menunjukkan responden memahami bahwa perawatan gigi tiruan bermanfaat bukan saja menggantikan gigi yang hilang namun perawatan gigi tiruan mampu meningkatkan fungsi bicara. Penulis berpendapat bahwa alasan responden tidak menggunakan gigi tiruan lebih dikarenakan persepsi responden terhadap perawatan gigi tiruan bukan sebagai kebutuhan utama yang harus dipenuhi. Pendapat ini dilatarbelakangi oleh tingkat ekonomi responden yang bisa dikatakan rendah apabila dihubungkan dengan tingkat pendidikan yang sebagian besar berpendidikan SD hingga SMA $(99,61 \%)$.

Ekonomi merupakan salah satu faktor terpenting dalam membuat keputusan, terlebih mengingat biaya perawatan gigi tiruan yang bisa dikatakan relatif mahal. Karakteristik responden yang sebagian besar bermatapencaharian sebagai buruh pelabuhan, ataupun sebagai pedagang kecilkecilan dengan banyaknya tuntutan kebutuhan keluarga yang harus dipenuhi, membuat perawatan gigi tiruan bukan menjadi prioritas utama dalam kehidupan sehari-hari mereka.

\section{Prosedur perawatan gigi tiruan}

Skor penelitian rata-rata tentang persepsi responden terhadap prosedur perawatan gigi tiruan adalah 328,25 . Penilaian tersebut termasuk dalam kategori baik. Alternatif jawaban yang dipilih responden terbanyak memilih jawaban pada atribut setuju hingga amat sangat setuju. Hal ini menggambarkan bahwa sebagian besar responden yang adalah individu yang kehilangan gigi namun tidak menggunakan gigi tiruan telah paham tentang prosedur perawatan gigi tiruan.

Perawatan gigi tiruan bukan saja memerlukan biaya yang relatif mahal apalagi bagi para responden yang sebagian besar berpendidikan SD hingga SMA $(99,61 \%)$, juga merupakan perawatan yang memerlukan kunjungan bolakbalik.Hal ini wajar karena perawatan gigi tiruan memerlukan penanganan yang bertahap dan tidak bisa diselesaikan dalam satu kunjungan saja. Kondisi ini antara lain yang dapat merupakan penyebab sehingga responden tidak melakukan perawatan gigi tiruan untuk menggantikan giginya yang hilang.

Penulis berasumsi bahwa dengan tingkat pendidikan demikian sangat berkaitan erat dengan tingkat ekonomi responden. Pendapat ini didukung oleh penelitian yang dilakukan oleh Temitope dkk pada tahun 2004 yang menyimpulkan bahwa orang-orang dengan status pendidikan yang lebih tinggi cenderung lebih kaya dibandingkan dengan yang berstatus pendidikan lebih rendah. Hal ini terkait dengan kemampuan mereka untuk membayar biaya perawatan gigi dari waktu ke waktu. ${ }^{15}$ Hasil yang diperoleh juga menunjukkan bahwa sebagian besar paham bahwa dokter gigi merupakan tenaga yang memiliki keahlian atau kompetensi untuk melakukan perawatan gigi tiruan. Dokter gigi sebagaimana dalam Peraturan Menteri Kesehatan nomor 512/Menkes/Per/IV/2007 Tentang Izin Praktek dan Pelaksanaan Praktek Kedokteran menyebutkan antara lain bahwa dokter gigi adalah pemberi pelayanan medis sesuai kompetensi dan 
kewenangannya termasuk pelayanan rehabilitatif. Penulis berpendapat bahwa alasan responden tidak melakukan perawatan gigi tiruan lebih dikarenakan persepsi bahwa perawatan gigi tiruan

\section{SIMPULAN}

1. Persepsi masyarakat tentang tujuan perawatan gigi tiruan, baik

2. Persepsi masyarakat tentang manfaat gigi tiruan, baik

3. Persepsi masyarakat tentang prosedur perawatan gigi tiruan, cukup

\section{SARAN}

1. Bagi masyarakat diharapkan adanya upaya pemerintah untuk membantu meningkatkan status ekonominya sehingga masyarakat mampu untuk mencukupi kebutuhannya di bidang kesehatan terlebih khusus di bidang kesehatan gigi.

2. Adanya penelitian lebih lanjut dalam skala yang lebih luas agar bisa diperoleh data dasar yang bisa mewakili kondisi masyarakat di Sulawesi Utara untuk digunakan pihak pemerintah dalam upaya peningkatan derajat kesehatan gigi masyarakat.

\section{DAFTAR PUSTAKA}

1. The Global Health Observatory (GHO) is WHO's portal providing access to data and analysis for monitoring the global health situation. [serial online] 2013; [cited 21 April 2013].Availaiblefrom:

http://www.who.int/gho, accessed 10 March $\underline{2013}$

2. Bortoluzzi MC, Traebert J, Lasta R, Da Rosa TN, Capella DL, Presta AA. Tooth loss, chewing ability and quality of life.ContempClin Dent. 2012; 3:393-7.

3. Davis D. M, Fiske J, Scott B, Radford D.R. A study of the emotional reaction to tooth loss. Br Dent J. 2000; 188: 506-503.

4. KhazaeiS,Firouzi MS, SadeghpourSh, Jahangiri P,Savabi O, Keshteli AH, Adibi P. Edentulismand tooth loss in Iran : SEPAHANsystematic review No. 6. Int JPrev Med.[serial online] 2012; [cited 22 April 2013] :[42-7].Availaiblefrom: URL:

http://www.ncbi.nlm.nih.gov/pmc/articles/PM C3399303/

5. RisetKesehatanDasar [serialonline] 2007; [serialonline] 2007; [cited 22 April 2013].Available from: URL:http://www.scribd.com/doc/25886294/54 /Ke-sehatan-Gigi mahal, menyita waktu serta tidak nyaman. Persepsi ini menurut penulis terbentuk antara lain karena faktor pengalaman atau pengetahuan yang diadopsi dari lingkungan sekitar.

6. Natamiharja L. Status dankebutuhanpelayanankesehatangigilansia di kotamadya Medan. JurnalKedokteran Gigi Universitas Indonesia. [serial online] 2000; [cited 24 april 2013]; 7 (1): [14-22]. Available from:

URL:

http://repository.usu.ac.id/bitstream/12345678 9/7913/3/09E01533.pdf.txt

7. Notoatmodjo, S. PromosiKesehatandanIlmuPerilaku. Jakarta :RinekaCipta; 2007: 133-51.

8. Shigli K, Hebbal M, Angadi GS. Attitudes towards replacement of teeth among patients at the Institute of Dental Sciences, Belgaum, India. J Dent Educ. [serial online] 2007; [cited 24 April 2013]; 71 (11): 1467-75.Available from:

URL:

http://www.ncbi.nlm.nih.gov/pmc/articles/PM C3303920/

9. Battisttuzzi PGFCM, Keyser AF, Keltjens HMAM, Plasmana PJJM. Gigi tiruansebagiantitiktolakpada diagnose danperawatangigi-geligi yang rusak. Alihbahasa A I Kosasih, A R Kosasih. Editor SusiantiKentjana, LilianYuwono. Jakarta: WidyaMedika; 1996: 9-10.

10. Moynihan PJ The relationship between nutrition and systemic and oral well-being in older people Journal Am Dent Assoc [serial online] 2007; [cited 18 Agustus 2013]. Available from: URL: http://epubs.rcsi.ie/cgi/viewcontent.cgi?articl $\underline{e=1043 \& \text { context }=\text { medart }}$

11. Abidin T. Bukupanduanpelaksanaankegiatan di DesaBinaanPepsoden- FKG USU. Medan: USU Press. [serial online] 2009; [cited 12 Oktober 2013]: 2-3. Available from: URL: http://repository.usu.ac.id/bitstream/1234567 89/20284/2/Reference.pdf

12. Jubhari EH. Thinking pattern of first grade students towards edentulous replacement. Dent Journal. [serial online] 2007; [cited 12 Oktober]; 40: 65-9. Available from: URL: http://journal.unair.ac.id/detailjurnal.php?id= $1933 \&$ med $=2 \&$ bid $=3$

13. Sasmita SI, Riyanti E, Surachman B. Gigi tiruansebagianlepasananak.

Pertemuanilmiahilmukedokterangigi. [serial online] 2007; [cited 12 Oktober 2013]: 38-9. Available from: URL: http://pustaka.unpad.ac.id/wpcontent/uploads/2013/06/pustaka_unpad_efe 
$\underline{\text { ktivitas_daya_antibakteri_habbatussaudah.pd }}$ f

14. Fenn H. R. b, Gimson A. P, Liddelow K. P. Clinical Dental Prosthetics. Second Edition. [serial online] 1961; [cited 12 Oktober 2013]. Available from: URL: www.jdentistry.ui.ac.id/index.php/JDI/article /download/71/64
15. Esan T A, Olusile AO, Akeredolu PA and EsanAO.Socio-demographic factors and edentulism the Nigerian experience.J BMC Oal Health. [serial online] 2004; [cited 12 Oktober 2013]; 4(3):1-6. Available from: URL: $\underline{6831 / 4 / 3}$ 